\title{
DECADENCIA Y DEGRADACIÓN DE LAS MASAS FORESTALES VALENCIANAS
}

\author{
Cristina Montiel Molina
}

\section{RESUMEN}

El gran número de abusos que, con carácter secular, se han cometido en el espacio forestal valenciano ha generado un proceso de degradación progresiva de la cubierta vegetal, acentuado en los últimos decenios por la escalada de incendios forestales y las consecuencias de la especulación urbanística.

Entre las razones que justifican el estado actual de las masas forestales valencianas figuran, en primer lugar, los abusos revanchistas motivados por conflictos o cambios de titularidad desde época señorial y el deterioro ocasionado por aprovechamientos excesivos o desordenados. Los múltiples efectos que desencadenó la política desamortizadora, así como la expansión de las roturaciones arbitrarias, son igualmente fundamentales para entender el proceso de degradación que afecta desde mediados de la centuria pasada al espacio forestal valenciano.

Frente a los numerosos factores causantes de la degradación de los montes valencianos, las limitaciones impuestas por una guardería forestal insuficiente y el condicionamiento de unos intereses municipales a menudo contrapuestos a la conservación de la cobertura vegetal, han impedido o dificultado con frecuencia la defensa de los espacios montuosos.

\section{RÉSUMÉ}

Les nombreux abus qui ont eu lieu, depuis des siècles, dans l'espace forestier de la région de Valence ont provoqué un procéssus de dégradation progressive de la couverture végétale, aggravé pendant les dernières décennies par conséquent de l'escalade des feux de forêt et de la spéculation urbaine.

Parmis les raisons qui justifient l'état actuel des formations forestières valenciennes, il faut remarquer les excès revanchards liés aux conflits fonciers depuis l'époque segneuriale et la déchéance entraînée par des usages abussifs ou désordonnés. Le grand nombre d'effets déclanchés par le Désamortissement, ainsi que l'expansion des défrichements arbitrairs sont également fondamentaux pour comprendre le procéssus de dégradation qui afecte depuis la moitié du siècle dernier à l'espace forestier valencien.

Face aux plusieurs facteurs responsables de la dégradation des forêts valenciennes, les limitations impossées par le caractère insufissant du service de garde forestière et le conditionnement des intérêts communaux, souvent contraires à la conservation de la couverture végétale, ont évité ou difficulté fréquemment la défense des espaces forestiers. 
El estado actual de la cubierta vegetal de los montes valencianos es una de las mejores pruebas del proceso de degradación que han experimentado las masas forestales en esta región como consecuencia de usos indebidos, comportamientos inadecuados y actuaciones contraproducentes. Aunque la desamortización de los montes públicos es una de las principales causas de la degradación que secularmente ha experimentado el espacio forestal levantino, no conviene ignorar o despreciar otra serie de circunstancias que, derivadas de la privatización de los montes, o independientes de la misma, han contribuido por igual a su deterioro. De la frecuencia y pluralidad de los abusos e infracciones cometidos en el espacio forestal da buena muestra el notorio desarrollo adquirido desde tiempos medievales por la legislación sancionadora y, en particular, el gran número de denuncias formuladas al respecto desde mediados de la centuria pasada ${ }^{1}$.

El estado de decadencia que, como resultado de los abusos cometidos, sufrían a principios del siglo XIX los montes valencianos quedó reflejado en la Memoria premiada que contiene la indicación de los montes del Reyno de Valencia: clase, calidad, uso y abundancia ó escasez de sus maderas: ríos y carreteras que facilitan su extracción: causas de la decadencia de los bosques de este Reyno, medios de evitarla y de asegurar su permanencia, elaborada por Joaquín de la Croix y Vidal en 1801: «El Reyno de Valencia posee una cantidad considerable de Montes y bosques más o menos poblados de árboles que se reproducen por sí mismos; pero los continuos cortes, talas, y quemas exceden en número á los árboles que nacen espontáneamente» ${ }^{2}$.

Aquel balance negativo de la regeneración natural frente a la destrucción antrópica se ha perpetuado hasta nuestros días, dando lugar a «la ruina de los montes valencianos, más acentuada en general en los particulares que en los públicos» ${ }^{3}$. En 1932 el Distrito Forestal de Valencia, al evaluar el estado de decadencia de los montes de aquella provincia, tanto públicos como privados, consideraba numerosas y variadas causas: «En los primeros hay que citar incendios, muchos intencionados con miras a lucrativas cortas; las roturaciones indebidas en terrenos en que por su pendiente y pobreza, depues de aprovechar los pinos y tres o cuatro cosechas, se abandonan á la acción de las aguas pluviales que ocasionan en ellos asurcamientos primero y terminan por arrastrar su delgada capa de tierra vegetal; las cortas fraudulentas; el pastoreo con excesivo número de reses en relación con la posibilidad en pastos, practicado además sin orden y sin que se haya ejecutado una sola mejora en los pastos; causas agravadas por la carencia de la necesaria vigilancia» ${ }^{4}$.

La interpretación que ofrece J. de la Croix y Vidal acerca de las razones que justifican la degradación de los montes valencianos, a principios del siglo XIX, pone de manifiesto, por su paralelismo y coincidencia con las causas expuestas en 1932 por el Distrito Forestal de Valencia, la ineficacia de los medios utilizados para frenar o evitar aquel progresivo deterioro y el carácter endémico de los factores que ocasionaban la decadencia del espacio forestal ${ }^{5}$.

En definitiva, son múltiples y complejas las razones que contribuyen a explicar el estado actual de las masas forestales valencianas, puesto que la degradación de las mismas se debe a la imbricada intervención de un conjunto de factores de muy diversa índole.

1 Archivo de la Diputación Provincial de Valencia: Sección de Fomento, Subsección de Montes, legajos 21, 23 y 29: Archivo del Reino de Valencia: Sección «Propiedades Antiguas», legajos 1 y 36.

2 De la CROIX Y VIDAL, J.: Op. cit., Junta Pública de la Real Sociedad Económica de Amigos del País de Valencia, celebrada el día 9 de diciembre de 1880, Valencia, Imprenta de D. Benito Monfort, 1801, p. 175.

3 DISTRITO FORESTAL DE VALENCIA: Plan General de Trabajos para la formación del Catálogo de Montes Protectores o de Interés Social, 1932, p. 49 (Archivo de la Unidad Forestal de Valencia).

4 DISTRITO FORESTAL DE VALENCIA: Op. cit., 1932, pp. 48-49.

5 De la CROIX Y VIDAL, J.: Op. cit., p. 205. 


\section{Causas de la degradación de las formaciones vegetales}

\section{Abusos derivados de conflictos o cambios de titularidad}

En primer lugar, y por lo que respecta a la privatización de los montes públicos, hay que recordar la incidencia que la aplicación de las disposiciones desamortizadoras tuvo sobre el espacio forestal levantino, el cual, a resultas del cambio de titularidad, se vio expuesto a una explotación incontrolada y devastadora favorecida por la plena libertad de gestión que la ley establecía en los montes pertenecientes a particulares. Es significativa, en este sentido, la valoración que de la evolución experimentada por el monte de Utiel «Vinuerca y Cerro del Romeral», con posterioridad a su enajenación en pública subasta, realizaba el propio Distrito a fines del siglo XIX: «Desde que tuvo efecto la relacionada venta, ha venido el adquiriente utilizando aquellos terrenos sin hallar el menor obstáculo en el respeto de su posesión, descuajando por completo los pinares de la finca; y el Distrito forestal, al marcar los aprovechamientos comunes, ha sido otro de los que le secundaron, interponiendo su autoridad reglamentaria en los demás de la localidad.... ${ }^{6}$

También los pleitos antiseñoriales fueron causantes de abusos revanchistas por parte de los antiguos vasallos, quienes pretendían equivocadamente causar un perjuicio al titular del señorío arruinando la riqueza forestal de la comarca, cuya propiedad sostenía éste. Así ocurría a mediados del siglo pasado en el lugar de Torre-Alta, cuyo monte, perteneciente al Barón de Andilla, era objeto de múltiples ataques por parte del vecindario, como repetidas veces lo denunció su titular ${ }^{7}$. En el Gobierno Civil se registró igualmente en 1850 la denuncia formulada contra varios vecinos de Aliaquilla, a quienes les fueron aprehendidas once cargas y dos carros de maderas que conducían, procedentes de los montes de Utiel pertenecientes a la Marquesa de Moya ${ }^{8}$.

Más elocuente, si cabe, es la instancia dirigida aquel mismo año por el conde de Castellá al Gobernador Civil poniendo en conocimiento del mismo que poseía en el municipio de Fuente la Higuera una heredad compuesta de terreno cultivado y monte, respecto de la cual habían sido dictadas varias providencias para evitar la licencia que el vecindario se permitía de talar el arbolado y aprovechar arbitrariamente los pastos; pero que, sin embargo, los abusos habían alcanzado en el último año tal carácter, que la mayor parte del monte había resultado devastada, produciéndose constantes y violentos enfrentamientos entre los habitantes del término y los arrendadores del conde?

Otras veces eran los señores quienes, haciendo uso del derecho que les confería la titularidad de aquellos terrenos, concedían licencias para su aprovechamiento que, adicionadas a las que también expedía el ayuntamiento, arrogándose a su vez la propiedad de los montes, daban lugar a la sobreexplotación de aquellos predios. En estas circunstancias se encontraban, entre otros, los montes de Cortes de Pallás ${ }^{10}$.

6 Archivo del Reino de Valencia: «Propiedades Antiguas», legajo 12.

7 Archivo de la Diputación Provincial de Valencia: Sección de Fomento, Subsección de Montes, legajo 23.

8 Archivo de la Diputación Provincial de Valencia: Sección de Fomento, Subsección de Montes, legajo 20.

9 Archivo de la Diputación Provincial de Valencia: Sección de Fomento, Subsección de Montes, legajo 19.

10 Archivo de la Diputación Provincial de Valencia: Sección de Fomento, Subsección de Montes, legajo 5 . 
Las mancomunidades de aprovechamientos forestales entre los municipios colindantes también tuvieron, por lo general, efectos negativos sobre el estado de conservación de las masas forestales, puesto que dieron origen a frecuentes conflictos de intereses entre los pueblos copartícipes, que habitualmente expresaron mediante explotaciones abusivas los derechos que, a su juicio, les asistían para participar en los beneficios del monte. En 1839 el Ayuntamiento de Alfarbe denunciaba los excesos cometidos por los vecinos de Llombay en los pinares del despoblado de Aledua, que ambos municipios aprovechaban mancomunadamente. Según el recurrente, los habitantes de Llombay habían «destrozado y talado los pinos, leñas, esparto y demas a vista y conciencia de su justicia quien segun la espresión general recauda algunas cantidades por licencias que sin autorización concede á los vecinos de Picassent y otros puntos para el corte de leñas en dicho despoblado» ${ }^{11}$. Algo similar ocurría en los montes del término de Vallada, aprovechados mancomundamente por los vecinos de aquel municipio y los de Montesa. Según exponía en 1848 el alcalde de Vallada ante el Gobierno Civil, aquella mancomunidad era muy perjudicial para su pueblo, puesto que los vecinos de Montesa comerciaban con las leñas bajas que extraían, vendiendo a diario más de 1.000 cargas en Játiva, lo que constituía una seria amenaza para la cubierta vegetal de aquellos montes ${ }^{12}$.

El daño causado a los montes de la región por la práctica ganadera ha sido otro de los aspectos que con mayor frecuencia han denunciado los ingenieros del ramo y cuantos les han precedido en la responsabilidad de garantizar la mejora y el fomento de las masas arboladas. Según el informe elaborado en 1849 por el Comisario de Montes y Plantíos de la Provincia de Valencia, los ganaderos acostumbraban a aprovechar todos los pastos existentes en la mayor parte de los pueblos valencianos, fuera cual fuere su pertenencia, perjudicando de esta manera a los vecinos de los respectivos términos y propiciando la roza de los terrenos forestales para acelerar el crecimiento de las hierbas.

Los efectos desencadenados por el aprovechamiento abusivo de los pastos se evidencian en la práctica totalidad de los montes levantinos. Refiriéndose a los montes comunes de Murviedro, el ingeniero que en 1850 dirigió la poda del estrato arbóreo ponía de manifiesto que «en las cumbres y en las vertientes de algunos de aquellos cerros, formados por rocas de devoniano crecen espontánemente pinos de la clase ródenos y carrascos aunque con una lánguida vegetación, efecto de la costumbre existente de permitir pastar a los ganados cabríos y vacunos, los cuales se nutren de los brotes que producen los árboles ante la escasez de plantas herbáceas .... ${ }^{13}$.

Otra de las alusiones al menoscabo de las masas forestales ocasionado por una incontrolada y extralimitada práctica ganadera es la que en 1877 realizaba el ingeniero que redactó la Memoria de Reconocimiento del monte «Puntal de los Caracoles», radicado en el término de Venta del Moro: «Se halla repoblado por el pino carrasco, pero espaciados y por esta circunstancia raquíticos y achaparrados, a cuyo deplorable resultado contribuye también muy eficazmente el inmoderado uso que hasta aquí se ha hecho del pastoreo» ${ }^{14}$.

Al pastoreo atribuían también los vecinos de Alcoy la degradación que sufría el «Carrascal», logrando con sus denuncias que el Ayuntamiento prohibiese el aprovechamiento

11 Archivo de la Diputación Provincial de Valencia: Sección de Fomento, Subsección de Montes, legajo 2.

12 Archivo de la Diputación Provincial de Valencia: Sección de Montes, legajo 13. 19.

13 Archivo de la Diputación Provincial de Valencia: Sección de Fomento, Subsección de Montes, legajo

14 Archivo de la Unidad Forestal de Valencia: Expediente del monte de utilidad pública ${ }^{\circ} 98$. 
de pastos en el predio para favorecer la regeneración de la vegetación natural. Los propietarios ganaderos del término dirigían a la Alcaldía hacia 1826 escritos de protesta contra aquellas medidas donde, paradójicamente, admitían el perjuicio que la práctica del pastoreo había causado al monte, fundamentando su petición precisamente en el estado ruinoso en que, según afirmaban, se encontraba aquél: «...en todos tiempos se ha permitido el introducir el ganado lanar en el Monte Carrascal de este termino á pacer y comer la mucha yerba que se cria, pero hace pocos años se ha prohibido absolutamente al parecer por las cortas que se observavan y se atribuían á los Pastores y Ganaderos, pero en el día baxo nungún aspecto se puede sostener dicha prohibición, porque además que el referido Monte se halla enteramente talado y destruido, es mucha la yerba ó pasto que ha producido la tierra, lo qual al paso que espone el Carrascal á un incendio, impide tambien el fomento y medro del arbolado por lo que lexos de ser perjudicial la introducción del ganado lanar sera sumamente util al arbolado al qual no causa ningún daño...» ${ }^{15}$.

\section{Repercusiones de la gestión inadecuada de los montes municipales}

Las concesiones que algunos ayuntamientos realizaban a los vecinos indigentes del término para que, aprovechando los productos forestales, pudiesen complementar su economía doméstica y asegurar la subsistencia, así como los aprovechamientos extraordinarios que se realizaban con motivo de la ejecución de alguna obra de utilidad pública, del pago de algún impuesto o del saldo de la deuda adquirida con el antiguo titular del señorío en el acto de compra-venta del monte o redención de los derechos señoriales, daban origen también a excesos de los que dimanaban perjuicios irreparables para las masas forestales. El alcalde de Montesa, por ejemplo, reconocía en 1835, en oficio dirigido al Gobernador Civil respecto al menoscabo que la corta y arranque de árboles había causado a la agricultura del término, que la miseria del vecindario había sido uno de los motivos fundamentales del estado de decadencia de los montes: «...que todo dimana de la infidelidad y pobreza de aquella villa que por los muchos pagos que está sufriendo, se encuentran sus vecinos en una pura miseria sin poder sustentar á sus familias ni satisfacer las contribuciones, no teniendo otro arbitrio que cortar los árboles y vender la leña en la ciudad de San Felipe...» ${ }^{16}$.

En otros casos, la arbitrariedad del ayuntamiento no respondía a la precariedad económica del vecindario, sino a la necesidad o ambición de la corporación por recaudar fondos para sufragar gastos municipales. En estas circunstancias el objetivo real del ayuntamiento no era asegurar la conservación de los montes, sino sacar el máximo provecho de los mismos, lo que, a menudo, ocasionaba la desaparición del estrato arbóreo y la degradación de los pisos arbustivo y herbáceo. A este factor, entre otros, atribuye el ingeniero que en 1899 practicó el reconocimiento de «La Sierra» de Cuatretonda la ruina de la masa arbórea del término, explotada para obtener fondos con que sufragar las obras de conducción de aguas potables del municipio ${ }^{17}$.

En 1835 varios vecinos propietarios del pago de Machuquera del término de Gandía dirigían al Gobierno un escrito acusatorio contra al Ayuntamiento solicitando la supresión del arbitrio que la Corporación percibía a cambio de la concesión de licencias a los

15 Archivo Histórico Municipal de Alcoy: Sección III, 15, 5.

16 Archivo de la Diputación Provincial de Valencia: Sección de Fomento, Subsección de Agricultura y Ganadería, legajo 3, expediente 54.

17 Archivo de la Unidad Forestal de Valencia: Expediente del monte de utilidad pública $\mathrm{n}^{\circ} 16$. 
ganaderos trashumantes para aprovechar los pastos del término, por considerar que el uso de tal arbitrio resultaba perjudicial para el municipio ${ }^{18}$.

Con objeto de prevenir los abusos que, en concepto de arbitrios, permitían y favorecían los ayuntamientos en sus respectivos términos, el 17 de noviembre de 1841 fue promulgada una Real Orden que prohibía «hacer por ningún pretexto descuajes, rompimientos, ni corta alguna en los montes de propios y comunes ni en los demás que estén al cuidado de los ayuntamientos, sin que preceda la instrucción del espediente en debida forma el cual se pase a la Diputación Provincial, remitiendo esta su informe por conducto del Jefe Político a la Dirección General» ${ }^{19}$. Fue corriente, sin embargo, la inobservancia de esta disposición, puesto que los ayuntamientos continuaron actuando a su libre albedrío en la mayor parte de los casos. Otras veces formulaban la solicitud preceptiva para aprovechar los productos forestales del término, aunque no respetaban la resolución de la misma en caso de serles denegada.

Los dictamenes del Gobierno Civil, por otro lado, tampoco eran siempre del tono que convenía a la conservación de los montes de la provincia, como evidencia el pronunciamiento del Gobierno Civil de Alicante a una solicitud formulada a fines del siglo pasado por el Ayuntamiento de Vall de la Gallinera para llevar a cabo la enajenación de las leñas bajas, que no utilizaban los vecinos, del monte que pertenecía al común en aquel término ${ }^{20}$.

\section{La expansión de roturaciones arbitrarias}

La roturación de terrenos de vocación forestal con ánimo de extender las parcelas de cultivo para, de esta manera, incrementar el volumen de producción, ha sido otro de los procesos que mayor perjuicio ha ocasionado a los montes levantinos, por ser ésta una región de importante tradición agraria donde el espacio forestal ha sido concebido como elemento complementario en la economía de subsistencia, y al que no siempre se ha valorado la función física que desempeña en su entorno.

Son múltiples las denuncias de roturaciones arbitrarias y apropiaciones indebidas por parte de particulares colindantes que recibieron durante el siglo pasado las Comisarias de Montes y Plantíos y las Comisiones Provinciales ${ }^{21}$. Entre las más significativas se encuentra la formulada en 1861 por el guarda mayor de la comarca de Carlet respecto al abuso cometido por un vecino de Turis en los montes blancos del término de Montroy al roturar parte de su extensión, para lo que hubo de arrancar «unos 147 pies de pinos pimpollos de la clase carrasco» ${ }^{22}$.

También con motivo de la formación de la Estadística de los Montes Estatales a mediados del siglo XIX, varios municipios de la región expresaron las consecuencias que las roturaciones habían ocasionado en los montes de sus respectivos términos. Con anterioridad a la ejecución de aquellos trabajos existen igualmente alusiones a los perjuicios causados por la roturación de terrenos de vocación forestal. En 1838, por ejemplo, un vecino de Bugarra denunciaba los abusos de roce y desmonte para labores de siembra que se estaban cometiendo en el «coto de pinos reservado» denominado «La Umbría» 23 .

18 Archivo de la Diputación Provincial de Valencia: Sección de Fomento, Subsección de Agricultura y Ganadería, legajo 3, expediente 60.

19 Archivo de la Diputación Provincial de Valencia: Sección de Fomento, Subsección de Montes, legajo 5.

20 Archivo de la Diputación Provincial de Alicante: Sección de Fomento, legajo 219.

21 Archivo de la Diputación Provincial de Valencia: Sección de Fomento, Subsección de Montes, legajos 15-16-18-23; Archivo del Reino de Valencia: Sección «Propiedades Antiguas», legajos 1 y 75.

22 Archivo de la Unidad Forestal de Valencia: Expediente del monte «Comunal» de Montroy.

23 Archivo de la Diputación Provincial de Valencia: Sección de Fomento, Subsección de Montes, legajo 2. 
En 1852 manifestaba ante la Comisión Provincial de Valencia el Alcalde de Montserrat que algunos vecinos de Torrente, Picasent, Real de Montroy y Montroy del Real, terratenientes de Montserrat, se habían apropiado y habían roturado sin autorización parte de los montes pertenecientes al común en aquel término, «dejándolos reducidos a un espacio de terreno insignificante». Por las mismas fechas ponía en conocimiento de la Comisión el Alcalde de Montesa los abusos que del mismo tipo cometían en su municipio los vecinos de Ayelo de Malferit, terratenientes en Montesa ${ }^{24}$.

Más elocuente es, sin duda, el oficio dirigido en 1899 por el Ayuntamiento de Casas Altas a la Dirección General de Propiedades y Derechos del Estado, al serles notificado el inicio de las operaciones preliminares para la venta del monte de aquel término: «El monte de este término municipal «Lomas de los Corrales», se encuentra en la actualidad, como desde tiempo inmemorial, laborizado y dedicado al cultivo de cereales, sin que haya ningún pedazo de terreno inculto, poseyéndolo aunque en pequeñas porciones, bastante número de propietarios, hallándose amillarado á nombre de éstos, como dueños del mismo, en virtud de haberlo heredado, la mayoría de ellos, de sus antepasados, no habiendo sido nunca interrumpida la posesión, disfrutándola siempre quieta y pacifícamente $»^{25}$.

Los ingenieros de montes adscritos a la Administración de Propiedades y Derechos del Estado comprobaban también a finales de la centuria pasada que «en Paterna no existen ya superficies públicas: pues el Boalar ha sido totalmente roturado y de epocas bastante

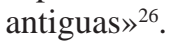

Cuando en 1864 Bosch y Juliá recorrió la cuenca hidrológica del Júcar para estudiar los efectos de la inundación ocurrida los días 4 y 5 de noviembre de aquel año, uno de los aspectos que más llamó su atención, según expresa en el capítulo dedicado a la «Reseña Forestal» de la comarca, fue precisamente la reducida extensión que en realidad poseían los montes, como resultado de los descuajes y roturaciones llevados a cabo en los mismos por particulares que habían accedido a la propiedad de aquellos en virtud de las disposiciones desamortizadoras ${ }^{27}$.

La proximidad de los montes a los núcleos de población ha sido igualmente un condicionamiento de signo claramente negativo para la conservación de la cubierta vegetal. La degradación de las masas forestales se ha producido en toda época de forma directamente proporcional al grado de accesibilidad del monte, siendo los espacios más alejados y peor comunicados aquellos que han logrado preservar algún reducto de vegetación de cierta importancia. Esta circunstancia ha sido puesta de manifiesto en repetidas ocasiones por los ingenieros del ramo al llevar a cabo el reconocimiento de los montes valencianos. La Comisión que en 1879 realizó los trabajos previos a la Rectificación del Catálogo de los Montes Públicos de 1862 en la Primera Sección de la Provincia de Valencia hizo diversas alusiones a la influencia del factor señalado en el estado de conservación de las formaciones vegetales. Refiriéndose al monte de Loriguilla situado a la izquierda del río Turia y conocido bajo la denominación de «Peña Alta», la Memoria elaborada por el Distrito de Valencia en 1879 expresaba que «su vegetación es y será siempre pobre, consecuencia de su proximidad al pueblo de Loriguilla $»^{28}$.

24 Archivo de la Diputación Provincial de Valencia: Sección de Fomento, Subsección de Montes, legajo 24.

25 Archivo del Reino de Valencia: Sección «Propiedades Antiguas», legajo 36.

26 Archivo del Reino de Valencia: Sección «Propiedades Antiguas», legajo 12.

27 BOSCH Y JULIA, M.: Memoria sobre la inundación del Júcar en 1864, Madrid, Imprenta Nacional, 1866 p. 277.

28 Rectificación del Catálogo de la Provincia (Archivo de la Unidad Forestal de Valencia). 
En el resultado de los trabajos que, con el mismo motivo, fueron verificados en el partido judicial de Liria queda igualmente patente la incidencia sobre la degradación de la cubierta vegetal de la distancia al núcleo de población ${ }^{29}$.

El consumo de carbón y de madera, sobre todo para la elaboración de envases destinados a la exportación de los productos agrarios de la región, que generaron las industrias valencianas fue otro de los motivos que contribuyeron a la destrucción de las masas arboladas. Este factor fue precisamente uno de los principales fundamentos de la destrucción de la masa forestal de Ademuz. En 1850 manifestaba el Alcalde de aquel término al Comisario de Montes del Provincia de Valencia que no se habían ejecutado en el mismo plantaciones, siembras ni aprovechamientos, por no existir montes en el municipio. Asombrado por aquella información relativa a un término municipal situado en una de las principales comarcas forestales de la región, el Comisario pidió la elaboración de un informe sobre el particular al Perito Agrónomo de la Provincia. El contenido de éste confirmó la certeza de la información suministrada por el Alcalde, al señalar que «los montes estan desnudos de leña, por consumirse ésta en una fábrica de fundición de azufre y por los excesos que cometen los vecinos de los pueblos comarcanos $»^{30}$.

\section{Infracciones cometidas en los montes públicos}

La extralimitación de quienes adquirían en pública subasta los productos forestales de los montes valencianos al verificar los aprovechamientos que les habían sido adjudicados, es otra de las razones que permiten entender la progresiva degradación de las formaciones vegetales en la región. Son frecuentes las alusiones a este tipo de abusos en las Memorias de Ejecución de los Planes Anuales de Aprovechamientos Forestales y en denuncias que sobre el particular formulaban los encargados de la guarda y custodia de los montes públicos. Uno de los múltiples ejemplos que existen al respecto es un informe transmitido al Alcalde de Tabernes de Valldigna por la Guardia Civil en noviembre de 1900, relativo al monte que, con el $\mathrm{n}^{\circ} 135$ y bajo la denominación de «Las Cruces y la Umbría», figura actualmente en el Catálogo de Montes de Utilidad Pública de la Provincia de Valencia. Según exponía la Guardia Civil, encargada de la custodia de aquel predio, «han sido cortados gran número de pinos a más de trescientos para que fué autorizado el rematante de esta vecindad Don Lino Pons Almiñana y que muchos de estos no se hallan marcados con el Sello del Distrito (...) practicado recuento de los cortados hasta la fecha, resulta ser el número de cuatrocientos sesenta y nueve, cortados a nivel de tierra y sin quedar vestigio ni

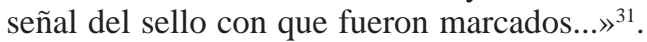

Los excesos cometidos en el ejercicio de los aprovechamientos se unían generalmente a las deficiencias de una guardería escasa e ineficaz lo que limitaba extraordinariamente la tarea de los ingenieros, tal y como en 1898 lo exponía el recién nombrado Ingeniero Jefe del Distrito de Valencia al Delegado de Hacienda de la Provincia: «no he podido encontrar dato alguno que sirva para determinar si la guardería de los montes á ella afectos se egerce con la debida vigilancia y si se hacen efectivas las responsabilidades contraidas tanto por los dañadores, como por los rematantes y usuarios en las extralimitaciones que efectuan al aprovechar los disfrutes que les están concedidos; continuando el servicio en esta forma no

29 Archivo de la Unidad Forestal de Valencia: Expediente del monte de utilidad pública ${ }^{\circ} 87$.

30 Archivo de la Diputación Provincial de Valencia: Sección de Fomento, Subsección de Montes, legajo 18.

31 Archivo del Reino de Valencia: Sección «Propiedades Antiguas», legajo 7. 
puede el que suscribe tomar aquellas medidas necesarias para la debida conservación de los montes, por desconocer que clase de daños se cometen y la cuantía de éstos... ${ }^{32}$.

Las consecuencias de los episodios bélicos se encuentran también en el origen de la degradación que han sufrido los montes valencianos. Son diversas las alusiones que a este aspecto hicieron los ingenieros que llevaron a cabo durante el último tercio del siglo pasado las tareas de rectificación del Catálogo de 1862 en la región valenciana, refiriéndose, en general, a la revolución de $1868^{33}$. Esta, las guerras carlistas y la guerra civil, son los procesos a que con más frecuencia aluden los ingenieros para explicar la desaparición del arbolado en los montes de la región ${ }^{34}$.

\section{Efectos de los incendios forestales}

Sin embargo, y a pesar de la importancia con que cuentan los diversos abusos citados, uno de los que mayor perjuicio ha ocasionado a las formaciones vegetales de la Comunidad Valenciana, por su efecto devastador y su carácter recurrente, han sido los incendios forestales. Constituye éste un riesgo tradicionalmente inherente a los montes mediterráneos, si bien hasta las últimas decadas no había adquirido la intensidad con que se manifiesta en la actualidad debido a la confluencia de factores de muy diversa índole, ajenos a menudo a la propia dinámica de las formaciones forestales. Entre las referencias más antiguas a la génesis y propagación de incendios en los montes valencianos destaca la que recoge el Acta de la Sesión celebrada el día 31 de agosto de 1718 por el Cabildo Municipal de Villajoyosa: «...que se comete de muchos años a esta parte en diversos sitios de este reyno las talas y quemas de los montes y especialmente lo segundo, con el motivo de que el incendio resulta que los pastos salgan con más fuerza y que los árboles quemados hechan junto al suelo tallos frescos y tiernos, que comen los ganados cabrunos, mejor que ningún otro pasto de lo que se consigue que las encinas y otros árboles no vuelvan a su antiguo estado...» $»^{35}$.

Hasta los últimos tiempos, los incendios forestales han estado relacionados, además de con causas naturales ligadas al elevado índice de inflamabilidad de la vegetación mediterránea, con las rozas realizadas por los pastores para favorecer el desarrollo de los pastos y con los conflictos existentes en los pueblos valencianos por cuestiones de titularidad o aprovechamiento de los montes. No son, por tanto, los incendios forestales, fenómeno exclusivo de las últimas décadas, como lo demuestran las medidas coercitivas y sancionadoras promulgadas sobre el particular desde tiempos medievales.

A pesar de no ser abundante ni completa la información existente al respecto, existe alguna alusión a incendios acaecidos durante el siglo pasado en montes de la región valenciana. Así, nos ha sido posible documentar una serie de incendios registrados a mediados del siglo XIX en la provincia de Alicante; en concreto, el incendio que destruyó

32 Archivo del Reino de Valencia: Sección «Propiedades Antiguas», legajo 36.

33 Archivo de la Unidad Forestal de Valencia: Expedientes de los montes de utilidad pública nº 35, 38 y 87.

34 Archivo de la Unidad Forestal de Castellón: Expedientes de los montes de utilidad pública n ${ }^{\circ} 18$ y 76; Archivo de la Unidad Forestal de Valencia: Expedientes de los montes de utilidad pública no 40 y 49 ; Archivo del Ministerio de Agricultura, Pesca y Alimentación: Fondos Documentales procedentes de la Sección de Montes de la Dirección de Agricultura, Sección «Planes de Aprovechamientos Forestales», Castellón 1876-77, legajo 13, expediente 1; Castellón 1890-91, legajo 78, expediente 8; Sección «Repoblaciones», legajo 385.

35 Libro de Deliberaciones (Archivo Municipal de Villajoyosa), cit. MARCO MOLINA, J. A.: El medio físico de Aitana. Análisis morfoestructural, condiciones bioclimáticas y formas de modelado, Tesis Doctoral dirigida por el Dr. D. Alfredo Morales Gil y defendida en la Facultad de Filosofía y Letras de la Universidad de Alicante en 1988, pp. 454-455. 
en 1840 la mayor parte de la vegetación arbórea del Carrascal de la Font Roja en Alcoy, dos siniestros producidos en la Vall de Ebo durante el primer semestre de 1848, otro ocurrido en Bañeres al año siguiente y un cuarto incendio registrado en Benejama durante los primeros meses de 1850, así como el incendio que en 1851 asoló «Las Lometas» de Monóvar $^{36}$. Significativa es igualmente la referencia que a este tipo de abusos realizaba en 1901 el ingeniero que elaboró el Proyecto de Deslinde de los «Montes Altos», «Navalón» y «La Redonda», que, en su conjunto, componen el monte denominado «La Sierra» perteneciente al municipio de Enguera: «...fueron acentuándose los descuajes y los incendios forestales hasta el punto de que a mediados del siglo XVIII tuvieron las Justicias de la Villa de Enguera que adoptar medidas para poner coto a semejantes desmanes, pues llegaron los fuegos a ser tan intensos que hubo casos en los cuales produjeron quejas los pueblos de la Ribera, por los daños que causaron a los arrozales...» ${ }^{37}$.

\section{Limitaciones en la defensa y protección de las masas forestales}

Los factores señalados como agentes principales de la degradación y devastación de los montes valencianos han actuado normalmente de forma conjunta, resultando difícil discernir los efectos atribuibles a cada uno de ellos, aunque en ciertas ocasiones es notorio el predominio de alguno en particular. La imbricación de todos ellos condujo a Bosch y Juliá en 1864 a calificar el estado de los montes de la cuenca hidrográfica del Júcar como «el más lastimoso que pueda imaginarse $»^{38}$.

Los únicos medios de que disponían en realidad los ingenieros para evitar o controlar los abusos cometidos en los montes públicos de su Distrito eran la guardería forestal y la inclusión de los predios públicos en los Catálogos de montes exceptuados primero, y entre los de utilidad pública más tarde, lo que en teoría garantizaba el respeto a las formaciones forestales. Ninguno de estos recursos dio, sin embargo, los resultados esperados, ya que los montes públicos continuaron expuestos en cualquier caso a toda clase de abusos e infracciones $^{39}$.

La ineficacia de la guardería forestal, debido generalmente a la sobrecarga de trabajo, fue repetidas veces denunciada por los Distritos. El Ingeniero Jefe del Distrito de Valencia insistía, en la Memoria Justificativa del Plan Anual de Aprovechamiento Forestales de 1873-74, en la necesidad de aumentar y mejorar las condiciones de la guardería de aquella provincia, opinando que «con 25 parejas de guardias civiles y dos jefes estarían mejor custodiados los montes del Distrito que con la actual guardería». No mejoró sin embargo la situación, ya que sólo dos años más tarde el mismo ingeniero lamentaba que «los aprovechamientos de las propuestas anuales son constantemente alterados por los incendios promovidos á intento por los pastores y por el aprovechamiento fraudulento de todas clases, que la escasa guardería es ineficaz de evitar, correspondiendo por término medio de 8 á 10.000 ha. de monte á un guarda, y añadiendo a ésto lo lento de los procedimientos judiciales en esta clase de delitos que quedan casi siempre sin castigo» ${ }^{40}$.

La desproporción existente entre el exiguo número de guardas encargados de la custodia de los montes y la vasta extensión que ocupaban los predios públicos, afectaba por

36 Archivo de la Diputación Provincial de Valencia: Sección de Fomento, legajo 45.

37 Archivo de la Unidad Forestal de Valencia: Expediente del monte de utilidad pública $\mathrm{n}^{\circ} 74$.

38 BOSCH Y JULIA, M. Op. cit., p. 279.

39 Archivo de la Unidad Forestal de Castellón: Expediente del monte de utilidad pública $n^{\circ} 62$.

40 Ministerio de Agricultura, Pesca y Alimentación: Fondos Documentales pertenecientes a la Sección de Montes de la Dirección General de Agricultura, Sección «Planes de Aprovechamientos Forestales», Valencia, 1873-74 y 1875-76, legajos 4-11, expedientes 8-7. 
igual a las otras dos provincias de la región. En Alicante, por ejemplo, según las cifras que ofrece la Estadística de la producción de los montes públicos en los años 1865-1870 respecto a la superficie media aprovechada anualmente en la provincia, los empleados destinados al Distrito y la relación existente entre ambas magnitudes, eran sólo siete los miembros del personal adscritos al ramo que se ocupaban de la custodia de las 86.774 hectáreas de superficie forestal que, por término medio, se aprovechaban cada año. De estos siete funcionarios, dos eran ingenieros integrantes del personal facultativo, otros dos sobreguardas y tres guardas ${ }^{41}$. En estas condiciones resultaba francamente ambicioso pretender garantizar la conservación y el fomento de los montes públicos ${ }^{42}$.

La evidente necesidad de sentar las bases de la formación de una guardería forestal suficiente y eficaz condujo a diversos tratadistas a elaborar proyectos como el que en 1863 remitía al Congreso de los Diputados la Sociedad Valenciana de Agricultura, y estudios tales como el publicado por Galofre en la Revista de Administración entre los años 1871 y $1872^{43}$.

Todos ellos resultaron a la postre infructuosos ante la carencia de recursos de las administraciones central y locales para sufragar el costo que suponía la organización del cuerpo encargado de garantizar la defensa de las formaciones forestales. Además, en muchos casos, los propios municipios se opusieron al nombramiento de guardas forestales por muy diversos motivos. Aunque el fundamental fue, en la mayoría de los casos, la falta de recursos por parte de las entidades municipales para sostener el salario de un guarda ${ }^{44}$, no faltan los ejemplos de negativa provocada por el interés del ayuntamiento en conservar las prerrogativas que le habían permitido hasta el momento hacer uso arbitrario de la riqueza forestal del término. En esta situación se encontraba, entre otros, el municipio de Llombay en 1839, según denunciaron los ayuntamientos de Alfarbe y Catadau, que sufrían los perjuicios ocasionados por los vecinos del primero en virtud de la antigua mancomunidad que estos pueblos sostenían respecto al aprovechamiento de los montes del despoblado de Aledua ${ }^{45}$.

La gravedad de las infracciones cometidas en los montes y la urgencia por atajar aquellos abusos suscitaron la promulgación de la Ley de 7 de julio de 1876, en virtud de la cual quedaba encomendada al cuerpo de la Guardia Civil la custodia de todos los montes públicos $^{46}$. No se logró tampoco de esta manera erradicar ni limitar los excesos que afectaban al ámbito forestal, como lo demuestra el enorme desarrollo que alcanzó la legislación sancionadora durante el último tercio del siglo XIX y principios de la centuria actual.

Las conclusiones aprobadas en los días 29 y 30 de noviembre y 1 de diciembre de 1907 de la Reforma de la Legislación Forestal, se ocupaban precisamente en el capítulo IV de la problemática inherente a la guardería de los montes e instituían las bases para la organiza-

41 MONTIEL MOLINA, C.: Los montes de utilidad pública en la provincia de Alicante, Caja de Ahorros Provincial de Alicante-Universidad de Alicante, 1990, p. 156.

42 DISTRITO FORESTAL DE ALICANTE: Estudio forestal de la provincia con motivo del Centenario del cuerpo de Ingenieros de Montes (1878-1949), t. I, pp. 275-276.

43 LASSALA Y PALOMARES, V.: Proyecto para la organización de la Guardia Rural presentado a la Sociedad Valenciana de Agricultura, Valencia, 1864, Imprenta de «La Opinión»; GALOFRE, J.: «Memoria y Proyecto para establecer una nueva guardería rural en España», Revista de Administración, 1871-1872, pp. 37-41, 97-103, 129-136, 161-167, 193-202.

44 MONTIEL MOLINA, C.: Op. cit., 1990, pp. 156-159.

45 Archivo de la Diputación Provincial de Valencia: Sección de Fomento, Subsección de Montes, legajo 2.

46 Archivo Histórico Municipal de Alcoy: Sección III.15.8.1., Actas de entrega de los montes municipales a la Guardia Civil. 
FIGURA 1. Estado natural de las masas forestales en la comunidad valenciana.

Fuente: GENERALIDAD VALENCIANA: Los incendios forestales en la Comunidad Valenciana, Valencia, Conselleria de Agricultura y Pesca, 1988, p. 225. 
Figura 2. Especies vegetales dominantes en los montes de la provincia de Castellón

PINAR

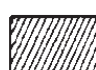

PINAR EN REGENERACION
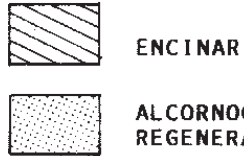

ALCORNOCAL EN

REGENERACION

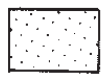

MATORRAL

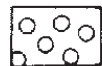

SAB I NA
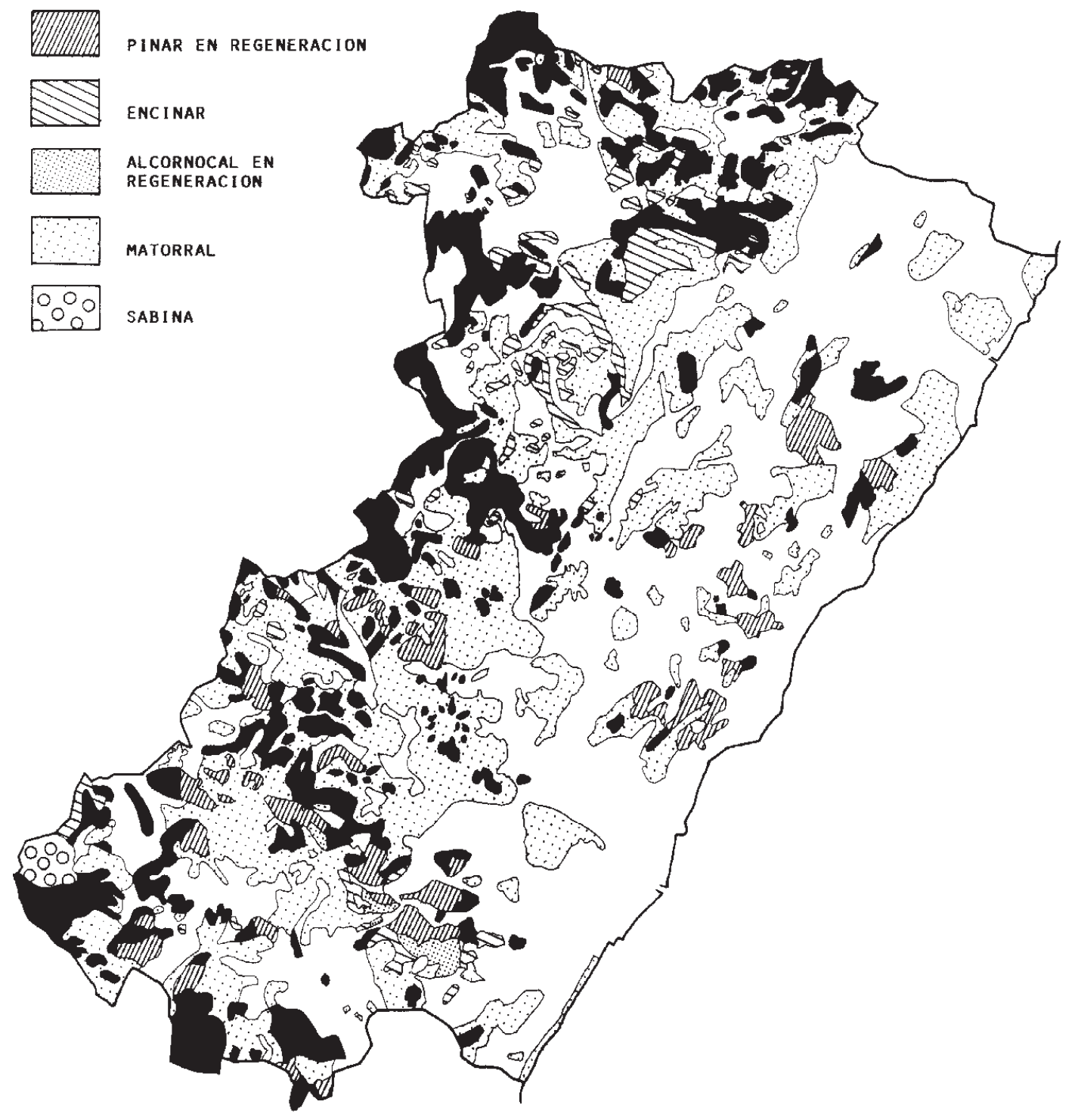

Fuente: Unidad Forestal de Castellón. 
ción del denominado «Cuerpo de guardas municipales de montes», que serían mantenidos con cargo al presupuesto municipal del término donde radicasen los predios custodiados ${ }^{47}$.

No debió resultar eficaz el sistema planteado por la Ley de 1907, según se infiere de las Observaciones que la Asociación de Ingenieros de Montes tiene el honor de elevar a la Comisión extraparlamentaria, con el ruego de que se sirva tenerlos en cuenta al redactar el Estatuto sobre la autonomía, que actualmente prepara. Los ingenieros proponían en la sexta de sus observaciones «que la Guardería forestal encargada de la custodia de los montes de utilidad pública sea nacional, y que la encargada de la vigilancia de los restantes montes de los pueblos no sea municipal; es decir, que en su nombramiento y disciplina no intervengan las Autoridades locales ${ }^{48}$.

La organización de una guardería forestal medianamente eficaz ha sido, por tanto, un asunto pendiente hasta fechas recientes que ha favorecido la degradación de los montes valencianos. Aún en la actualidad resulta imposible garantizar el cumplimiento de la normativa reguladora de los espacios forestales con los medios humanos de que se dispone para ejercer la vigilancia de los montes públicos, y con la forma en que se encuentran organizados los mismos, siendo uno de los mejores indicadores de estas limitaciones el elevado número de incendios forestales que anualmente se registran en la región y las infracciones que, acordes con la dinámica socioeconómica actual, siguen cometiéndose en estos predios.

El estado actual de los montes de utilidad pública valencianos es la prueba que mejor ilustra las deficiencias que tradicionalmente ha mostrado la guardería forestal en la región y las repercusiones sobre las formaciones vegetales de los abusos cometidos en estos espacios desde tiempos remotos, notoriamente incrementados durante los dos últimos siglos.

La toponimia y el contraste entre la imagen que presentaban los montes valencianos a principios de la centuria pasada y la que ofrecen hoy en día son dos de las manifestaciones que con mayor claridad hacen patente la degradación que han experimentado las formaciones forestales en la región. Abunda en la misma el topónimo «Carrascal» o «Carrascals», derivado del predominio de la especie que daba nombre al monte. En la actualidad suele ser unicamente la denominación, individuos aislados, y a lo sumo algún rodal con carácter relicto, el testimonio de una riqueza forestal ya desaparecida. Este es el caso, entre otros, del monte $\mathrm{n}^{\circ} 30$ del Catálogo de la Provincia de Castellón, acerca de cuya denominación y cubierta vegetal se pronunciaba de la siguiente manera el ingeniero que elaboró la Memoria de Reconocimiento en 1886: «Se atribuye su denominación de Carrascal a que ántes dominaba el encinar ó carrascal al pinar, que al presente domina por sustitución á beneficio de abusos en el encinar» ${ }^{49}$.

No menos significativo es el contraste entre la descripción que sobre el particular realizaba el ingeniero que por las mismas fechas elaboró la Memoria de reconocimiento del monte «Sierra Negra» de Villafranca y el estado natural que muestra el predio en la actualidad, con una cubierta vegetal de reducida densidad y con un claro predominio de la Juniperus oxycedrus y de la Juniperus communis sobre el Pinus laricio: «...el monte de que se trata recibe su nombre de que ya en la antigüedad, formaba una espesa masa de monte pinar que le daba un carácter sombrío y oscuro, ya visto a alguna distancia, aparecía cubierta como por un espeso manto negro...» $»^{50}$.

47 «Reforma de la Legislación Forestal», Revista de Montes, 1907, n 742, pp. 736-737.

48 «El problema de la autonomía municipal», Revista de Montes, 1919, n 11.009, p. 90.

49 Archivo de la Unidad Forestal de Castellón: Expediente del monte de utilidad pública no 30.

50 Archivo de la Unidad Forestal de Castellón: Expediente del monte de utilidad pública $\mathrm{n}^{\circ} 42$. 
Refiriéndose a la comarca septentrional de la provincia de Castellón, J. de la Croix y Vidal señalaba en 1801 la abundancia de «maderas de pino de estos montes, y la mucha de carrasca, y de roble». Con respecto a la Gobernación de Peñíscola, en concreto, destacaba la riqueza en «maderas de roble, y de encina, producida en muchos núcleos de bosques» ${ }^{51}$. Son estas tierras más septentrionales de la Comunidad Valenciana las que en mayor medida han acusado la regresión de la riqueza forestal en breve espacio de tiempo y donde mayor gravedad alcanza este deterioro por la calidad que poseía la cubierta vegetal de aquellos montes ${ }^{52}$.

La sustitución de las especies características del bosque climácico por otras propias de las formaciones subseriales mediterráneas, el predominio del monte bajo sobre el piso arbóreo y la degradación de la superficie tradicionalmente destinada a pastos, son, en definitiva, las notas dominantes en un espacio forestal que ha sido objeto de constantes abusos con carácter multisecular.

51 DE LA CROIX Y VIDAL, J.: Op. Cit., pp. 192-193.

52 Archivo de la Unidad Forestal de Castellón: Proyecto de Ordenación del monte «La Tenalla» del Estado (1930) y expediente del monte de utilidad pública $\mathrm{n}^{\circ} 2$. 